\title{
Blends of nitrile butadiene rubber/poly (vinyl chloride): The use of maleated anhydride castor oil based plasticizer
}

\author{
Indiah Ratna Dewi*, Ihda Novia Indrajati, Ike Setyorini \\ Center for Leather, Rubber, and Plastics, Jl. Sokonandi No. 9, Yogyakarta 55166, Indonesia \\ *Corresponding author: Tel.: +62 274 512929, 563939; Fax: +62 274563655 \\ E-mail: indiah.dardanela@gmail.com
}

Received: 15 January 2016 Revised: 31 May 2016 Accepted: 1 June 2016

\begin{abstract}
Recently, much attention has been focused on research to replace petroleum-based plasticizers, with biodegradable materials, such as biopolymer which offers competitive mechanical properties. In this study, castor oil was modified with maleic anhydride (MAH) to produce bioplasticizer named maleated anhydride castor oil (MACO), and used in nitrile butadiene rubber (NBR)/poly vinyl chloride (PVC) blend. The effect of MACO on its cure characteristics and mechanical properties of NBR/PVC blend has been determined. The reactions were carried out at different castor oil (CO)/xylene ratios, i.e. 1:0 and 1:1 by weight, and fixed CO/MAH ratio, 1:3 by mole. DOP, CO, and MACO were added into each NBR/PVC blend according to the formula. It was found that the viscosity and safe process level of NBR/PVC blend is similar from all plasticizer, however, MACO (1:0) showed the highest cure rate index (CRI). MACO-based plasticizer gave a higher value of the mechanical properties of the NBR/PVC blend as compared to DOP based plasticizer. MACO (1:1) based plasticizer showed a rather significance performance compared to another type of plasticizers both before and after aging. The value of hardness, elongation at break, tensile strength, and tear strength were 96 Shore A, 155.91 \%, 19.15 MPa, and 74.47 MPa, respectively. From this result, NBR/PVC blends based on MACO plasticizer can potentially replace the DOP, and therefore, making the rubber blends eco-friendly.
\end{abstract}

Keywords: esterification, castor oil, maleic anhydride, NBR/PVC blends, plasticizers

\section{INTRODUCTION}

Plasticizers are organic substances which are added to a polymer to increase its flexibility, processability or distensibility (Jia et al., 2015), to improve its softness, stretch, and flexibility in low temperature, and to decrease the intermolecular force concentration and glass transition temperature of the polymer. Common plasticizers are petroleum derived oils. High aromatic oils have traditionally been the most widely used extender oils for rubber and tyres due to their good compatibility with most of the common natural and synthetic elastomers and their low prices (Dasgupta et al., 2009). Unfortunately, they contain a large amount of polycyclic aromatic (PCA) substances, thus are identified as a carcinogen and toxic towards aquatic organism and its environment (Jiang et al., 2015). Another petroleum based oil plasticizer is phthalate which has been used since the 1930s. Phthalate is a common plasticizer used in NBR (Singh \& Bhattacharya, 2011), which is the most widely used plasticizers in PVC ( $\mathrm{Li} \&$ Ko, 2012). The uses of phthalate are currently being limited, because these compounds present potential risks to human health and the environment (Erythropel et al., 2015; Jia et al., 2015; Li \& Ko, 2012; Sander et al., 2012; Shi et al., 2011). Hence, there is a great incentive to develop green replacement plasticizers to reduce crude oil consumption while simultaneously maintaining plasticizing efficiency and eliminating or reducing toxicity to various organisms.

Vegetable oil is one potential source to substitute petroleum derived plasticizer. It originates from a non-toxic, biodegradable, and renewable resource. The application of vegetable oil in the polymer has been studied. Several vegetable oils which have been observed as rubber compound plasticizers are rubber seed oil, cashew, soybean, mustard, groundnut, neem, dolma, alsi, and castor oil (Dasgupta et al., 2007). Castor oil (CO) is produced from the castor bean (Ricinnus communis 
$L)$. It is a toxic vegetable, thus inconsumable. Esterification of $\mathrm{CO}$ and MAH will produce MACO. MACO has recently been used as a biomodifier on unsaturated polyester resin (UPE) and fly ash (Ghorui et al, 2011) to make an environmentfriendly composite with jute fiber (Mistri et al., 2011) and a composite with epoxy resin reinforced with fly ash (Ray et al., 2012). However, there was no research on using MACO as plasticizer in NBR/PVC blends. Therefore in this study, MACO was applied as a plasticizer on NBR/PVC blends, as a single plasticizer or combine with DOP plasticizer. The effects on its cure characteristics and mechanical properties were also studied.

\section{MATERIALS AND METHODS Materials}

Materials used in this research i.e. materials for MACO synthesis, and for NBR/PVC blends. Castor oil (Thai castor oil), xylene were purchased from Bratachem, and maleic anhydride was purchased from Multi Citra Chemindo Nusa. The rubber compound comprised as NBR Krynac 4975F, carbon black N-330 (OCI, Korea), carbon black N-774 (OCI, Korea), aflux 42M (RheinChemie), polimerized2,2,4-trimethyl-1,2-dihydroquinoline (Kemai), paraffin wax Antilux 65 A, 6PPD, MBTS (Shandong Sianxian), TMTD, sulfur SP-
325 (Miwon) which were purchased from Multi Citra Chemindo Nusa, PVC powder with K-value of 65 from WMK, active $\mathrm{ZnO}$ (Indoxide) from Bratachem, and DOP from Indrasari. All reagents were technical grade.

\section{Methods}

Synthesis of MACO

$\mathrm{CO}$ adducts were prepared by $\mathrm{CO}$ with $\mathrm{MAH}$ in a fixed $\mathrm{CO} / \mathrm{MAH}$ mole ratio of 1:3 by mole. Esterification reactions were carried out in a threeneck flask equipped with a dean stark apparatus, a cold water condenser, a magnetic stirrer, and a thermometer. A mixture of castor oil and xylene (at a ratio of 1:0 or 1:1 by weight) was added into the three-necked flask and heated to $140^{\circ} \mathrm{C}$. Then, a portion of MAH was incrementally added to the mixture and the reaction took place for $5 \mathrm{~h}$ at 300 rpm. Afterward, xylene was removed by vacuum distillation.

\section{Preparation of the NBR/PVC blends}

The formulations of the blends are given in Table 1. Variations were made on the types of plasticizer, DOP, castor oil, MACO (1:0), MACO $(1: 1)$ as a single plasticizer and its combination with DOP. All ingredients were mixed in a laboratory scale two roll mill. The product was then soaked in a sink filled with water in order to avoid

Table 1. Formulation of NBR/PVC blends.

\begin{tabular}{lccccccc}
\hline \multirow{1}{*}{ Materials } & \multicolumn{7}{c}{ Blend (phr) } \\
\cline { 2 - 8 } & 1 & 2 & 3 & 4 & 5 & 6 & 7 \\
\hline NBR & 70 & 70 & 70 & 70 & 70 & 70 & 70 \\
PVC powder & 30 & 30 & 30 & 30 & 30 & 30 & 30 \\
N-330 & 20 & 20 & 20 & 20 & 20 & 20 & 20 \\
N-774 & 40 & 40 & 40 & 40 & 40 & 40 & 40 \\
ZnO & 5 & 5 & 5 & 5 & 5 & 5 & 5 \\
Aflux & 1 & 1 & 1 & 1 & 1 & 1 & 1 \\
TMQ & 1 & 1 & 1 & 1 & 1 & 1 & 1 \\
6PPD & 0.5 & 0.5 & 0.5 & 0.5 & 0.5 & 0.5 & 0.5 \\
Flame retardant & 0.2 & 0.2 & 0.2 & 0.2 & 0.2 & 0.2 & 0.2 \\
Stearic calcium & 1 & 1 & 1 & 1 & 1 & 1 & 1 \\
Paraffin wax & 0.5 & 0.5 & 0.5 & 0.5 & 0.5 & 0.5 & 0.5 \\
DOP & 6 & 0 & 0 & 0 & 3 & 3 & 3 \\
Castor oil & 0 & 6 & 0 & 0 & 3 & 0 & 0 \\
MACO (1:0) & 0 & 0 & 6 & 0 & 0 & 3 & 0 \\
MACO (1:1) & 0 & 0 & 0 & 6 & 0 & 0 & 3 \\
MBTS & 1.2 & 1.2 & 1.2 & 1.2 & 1.2 & 1.2 & 1.2 \\
TMTD & 0.4 & 0.4 & 0.4 & 0.4 & 0.4 & 0.4 & 0.4 \\
DPG & 0 & 0 & 0 & 0 & 0 & 0 & 0 \\
Sulfur & 0.9 & 0.9 & 0.9 & 0.9 & 0.9 & 0.9 & 0.9 \\
\hline
\end{tabular}


premature crosslinking. Afterward, it allowed to mature for $24 \mathrm{~h}$ before subsequence processes and stored in a dry place at $25^{\circ} \mathrm{C}$. The vulcanization of the test slabs was done in a hydraulic press at 15 $\mathrm{MPa}$ and at defined temperature and time.

\section{Cure characteristics}

Cure characteristics were studied by using Moving Die Rheometer (MDR) Gotech 3000A at a frequency of $100 \mathrm{cpm}$ and an angle of $3 \mathrm{deg}$. Cure tests were performed at $170^{\circ} \mathrm{C}$. This study was conducted to determine scorch time ( $\left.\mathrm{ts}_{2}\right)$, optimum cure time $\left(\mathrm{t}_{90}\right)$, maximum torque $(\mathrm{MH})$, and minimum torque (ML). The cure rate index (CRI) of the mixtures was calculated according to Equation (1).

$$
\mathrm{CRI}=\frac{100}{\mathrm{t}_{90}-\mathrm{t}_{\mathrm{s} 2}}
$$

\section{Mechanical properties}

Hardness, elongation at break, tensile strength, and tear strength tests were done according to ISO 37 either original or after aging. The hardness test was performed using Durometer Hardness Tester and the tensile strength test was carried out with Kao Tieh Tensile Tester. Tests were performed at an extension rate of $50 \mathrm{~mm} / \mathrm{min}$ at $25^{\circ} \mathrm{C}$ and $50 \%$ relative humidity.

\section{RESULTS AND DISCUSSION Synthesis of MACO}

$\mathrm{CO}$ is a versatile vegetable oil. About $90 \%$ of its fatty acid content is 12-hydroxy-9-cis-octadecenoic acid. The rich chemistry of $\mathrm{CO}$ is attributed to its structure which makes it a good material for a range of applications such as plasticizer (Jia et al., 2015). In this study, CO is reacted with MAH to produce MACO. This reaction occurs in two stages. The first stage is fast (without condensation), non-catalytic, and first order with respect to each reactant, while the second stage (self-esterification with condensation) is a slow equilibrium reaction that can be catalyzed with acid and is enhanced by water removal (Mazo et al., 2012). The reaction mechanism of MACO synthesis is shown in Fig. 1. MACO reacts with a mixture of $\mathrm{CO}$ and xylene (a CO: xylene ratio of 1:0 by weight), according to the first stage reaction shown in Path 1, whereas the reaction between MACO and a mixture of $\mathrm{CO}$ and xylene (a ratio of 1:1 by weight) occurs in two stages, depicted in the Path 2 of Fig. 1. Since esterification is an equilibrium reaction, high reaction yield can be achieved by shifting the chemical equilibrium towards ester formation. According to the Le Chatelier principle, the yield and selectivity of the targeted reaction product are increased by removing the by-products. $\mathrm{H}_{2} \mathrm{O}$ is the by-product of MACO synthesis. Introducing xylene as a water trapper into the reaction system improves water removal. Xylene is water insoluble (solubility in water $<0.1 \mathrm{~g} / 1$ at $20^{\circ} \mathrm{C}$ ), thus, water/ xylene separation is feasible. Using the dean stark apparatus, $\mathrm{H}_{2} \mathrm{O}$ can be removed easily during the reaction; hence, the equilibrium is shifted to the MACO formation. In these experiments, water formation is initially observed when the dean stark apparatus becomes cloudy.

\section{Cure Characteristics}

The performance of the plasticizer in the NBR/PVC blends was evaluated based on their cure and mechanical characteristics. The cure characteristic of NBR/PVC blends and the effect

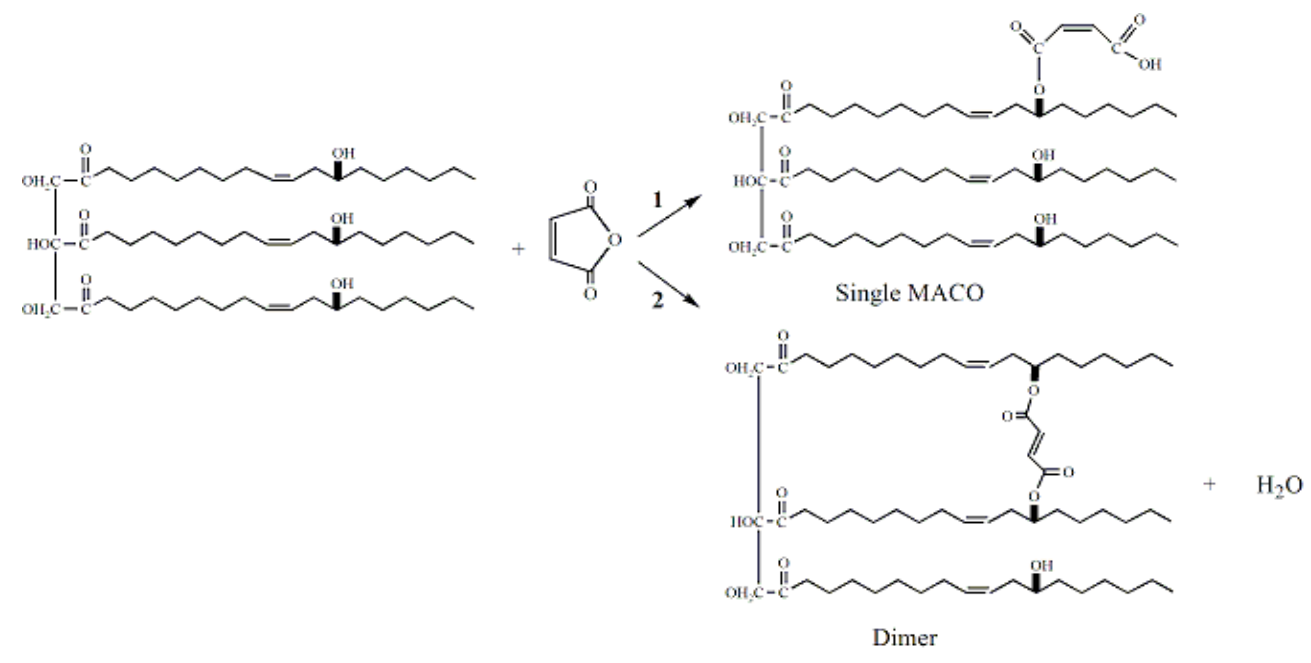

Fig. 1. Synthesis of MACO reaction mechanism. 
Table 2. Cure characteristics of NBR/PVC blends.

\begin{tabular}{lcccccc}
\hline \multicolumn{1}{c}{ Plasticizer } & $\begin{array}{c}\mathrm{MH} \\
(\mathrm{kg} . \mathrm{cm})\end{array}$ & $\begin{array}{c}\mathrm{ML} \\
(\mathrm{kg} . \mathrm{cm})\end{array}$ & $\begin{array}{c}\text { MH-ML } \\
(\mathrm{kg} . \mathrm{cm})\end{array}$ & $\begin{array}{c}\mathrm{ts}_{2} \\
(\mathrm{~s})\end{array}$ & $\begin{array}{c}\mathrm{t}_{90} \\
(\mathrm{~s})\end{array}$ & $\begin{array}{c}\text { CRI } \\
\left(\mathrm{s}^{-1}\right)\end{array}$ \\
\hline DOP & 76.13 & 13.58 & 62.55 & 19 & 187 & 0.595 \\
CO & 72.32 & 11.67 & 60.65 & 16 & 627 & 0.164 \\
MACO (1:0) & 64.91 & 12.40 & 52.51 & 18 & 172 & 0.649 \\
MACO (1:1) & 69.08 & 11.77 & 57.31 & 21 & 305 & 0.352 \\
DOP/CO & 77.43 & 11.84 & 65.59 & 21 & 444 & 0.236 \\
DOP/MACO (1:0) & 80.26 & 12.30 & 67.96 & 19 & 507 & 0.205 \\
DOP/MACO (1:1) & 82.54 & 13.59 & 68.95 & 18 & 733 & 0.140 \\
\hline
\end{tabular}

of the plasticizers on the minimum elastic torque (S'ML) and maximum elastic torque (S'MH) are shown in Table 2.

The maximum elasticity torque (MH) shows the maximum crosslinks which are formed during the vulcanization. The minimum torque (ML) indicates the compound's viscosity level (Surya et al., 2013). The difference in MH and ML values $(\Delta \mathrm{M}=\mathrm{MH}-\mathrm{ML})$ is a slide modulus which indirectly represents crosslink density. Each plasticizer provides a rather similar ML value, i.e. between 11-14 kg.cm. Therefore, all plasticizers have a similar processability. The addition of MACO gives a similar viscosity to DOP and CO. Higher viscosity will harden the next process. When it is used in a single form, MACO plasticizer is able to give lower $\mathrm{MH}$ compared to $\mathrm{CO}$ and DOP. However, when it is combined with DOP at 1:1 ratio, it is able to increase the MH value by $21.5 \%$. The ML values from all of the single plasticizers and their combinations are shown to be similar. Therefore, at the current condition, the crosslink density has the same trends as the MH value. The MACO/ DOP combination creates the highest crosslink density blend compared to other plasticizers.

Scorch time $\left(\mathrm{ts}_{2}\right)$ is a point where the crosslinks start to form and it is connected to a safe process. All studied plasticizers give similar scorch time, which indicates that the use of DOP, $\mathrm{CO}, \mathrm{MACO}$ and their combinations give similar safe processes, which are approximately in 19 seconds. The safe process is the time which a compound is able to stabilize at a high temperature and still in plastic properties. Scorch time marks a point where a plastic material starts to convert chemically into an elastic form. It represents the amount of heat history where a compound is able to undergo heating during forming and molding. The higher the $\mathrm{ts}_{2}$, the safer the process (Manoj et al., 2011). The minimum elastic torque ( $\mathrm{S}^{\prime} \mathrm{ML}$ ) is commonly considered as a representative of uncured stock's elastic modulus and provides valuable information about the processability of a compound (Nabil et al., 2013). S'ML is also a measure of stock viscosity (Surya et al., 2013).

The vulcanization optimum time $\left(t_{90}\right)$ as shown in Table 2, indicates the vulcanization reaction time to achieve the maximum torque (MH). The MACO (1:0) provides a similar $t_{90}$ value compared to DOP. Instead, the MACO (1:1) results in a $53 \%$ increase compared to DOP, and $77 \%$ compared to MACO (1:0). The increase in the $t_{90}$ value is due to the existing free acid groups in MACO (1:1) at the end of the process. The free acid groups are capable of decreasing the vulcanization reaction rate, therefore, the reaction time was longer. Free acid groups could be formed due to the incomplete consumption of MAH during the reaction. Unreacted MAH can react with water, which is formed during the second stage of the esterification reaction, to produce of maleic acid. This acid increases the acidity of MACO. The combined plasticizer gives a higher $\mathrm{t}_{90}$ value than a single plasticizer. The highest value of $733 \mathrm{~s}$ was obtained by the DOP/MACO (1:1) plasticizer.

The Cure Rate Index (CRI) as shown in Table 2 , is a reaction rate measurement based on $t_{90}$ and $\mathrm{ts}_{2}$. The higher CRI value makes the reaction faster (Al Minnath et al., 2011). MACO (1:0) gives a similar CRI value compared to DOP. Both of them create a higher CRI value compared to other plasticizers. A single MACO plasticizer creates a higher CRI value compared to $\mathrm{CO}$ and $\mathrm{DOP} /$ MACO combinations. The highest CRI value of $0.649 \mathrm{~s}^{-1}$ is created by MACO (1:0).

\section{Mechanical Properties}

The mechanical properties of the vulcanized NBR/PVC are presented in Figs. 2-5. Fig. 2 shows that the hardness of vulcanized NBR/PVC is similar to the other plasticizer, both before and after aging. However, a slight increase in the hardness 


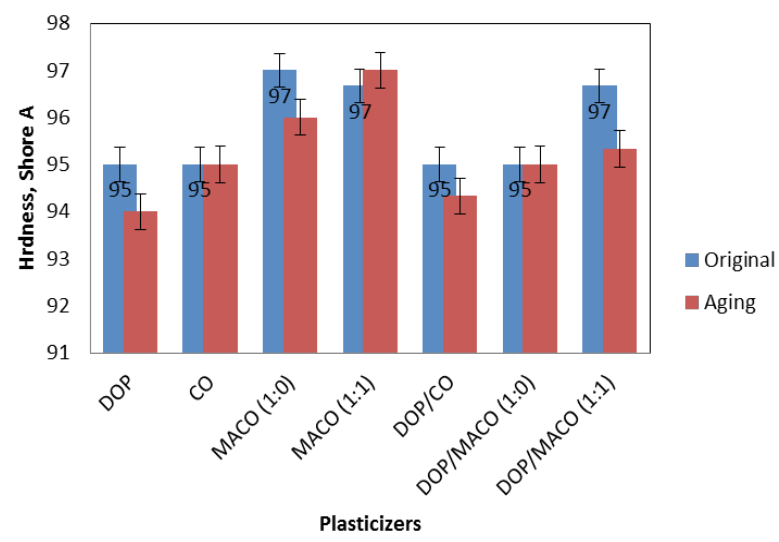

Fig. 2. Effect of plasticizers on hardness.

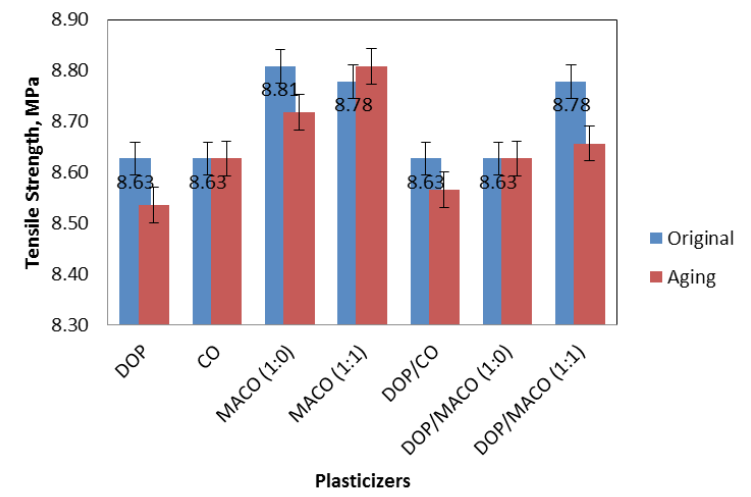

Fig. 4. Effect of plasticizers on tensile strength.

$( \pm 2 \%)$ of the vulcanized blend with MACO is able to improve its elasticity to $40.65 \%$ in comparison with DOP and up to $60.98 \%$ in comparison with CO. MACO could decrease the stiffness and brittleness of the blends associated with increasing the elasticity. It may be rather inferred that increase in the elasticity or lower elastic modulus/stiffness increases the adhesion strength or peel strength of the rubber blend composite (Sankaran et al., 2015). The aging properties also show a similar trend on the elasticity.The weakening matrix after thermal aging can decrease the elongation at break (Elhamouly, 2010).

Tensile strength determined for the samples of the vulcanized blends are presented in Fig. 4. It is found that the use of MACO (1:0) provides the higher tensile strength values, followed by MACO (1:1) and DOP/MACO (1:1) combination. Those three types of plasticizers affect the tensile strength in the most positive way. The use of MACO (1:0), MACO (1:1), and DOP/MACO $(1: 1)$ increase the maximum tensile strength until $17 \%$ in comparison to DOP, and $29.6 \%$ in comparison to $\mathrm{CO}$. The higher values of tensile

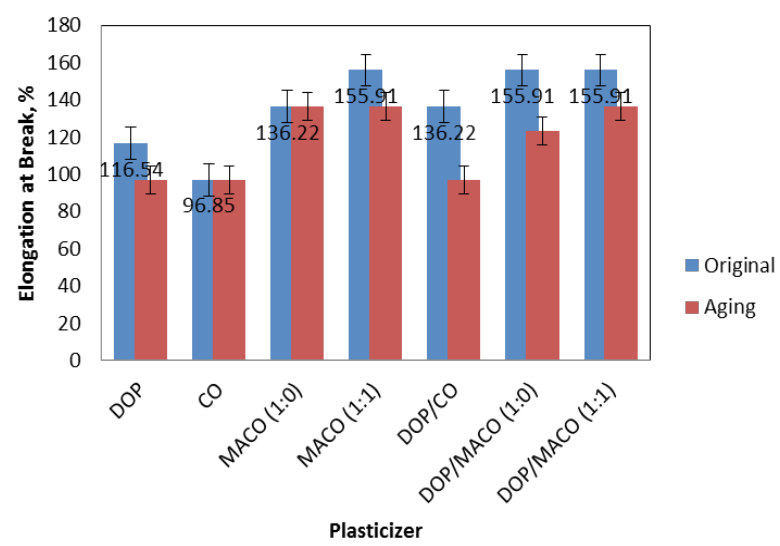

Fig. 3. Effect of plasticizers on elongation at break.

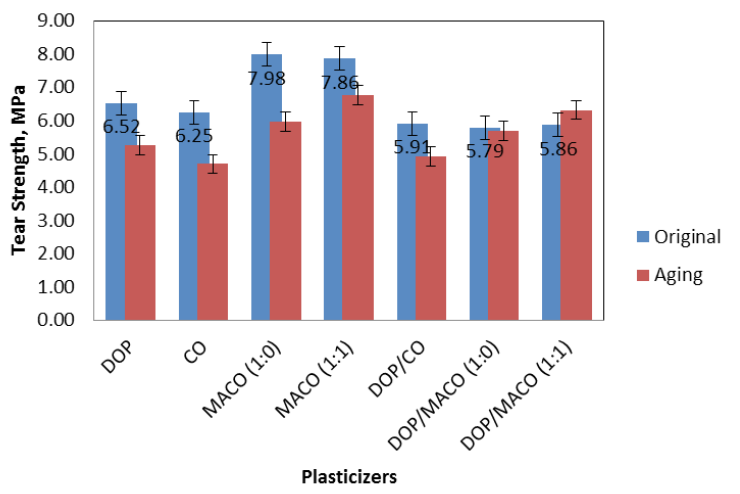

Fig. 5. Effect of plasticizers on tear strength.

strength may have been caused by the crosslink density in the NBR/PVC matrix and carbon black migration into the polymer matrix (Formela \& Haponiuk, 2014). This is in accordance with the curing characteristic of DOP/MACO (1:1), which has the highest ML and MH-ML value. As previously mentioned, ML may indicate processability and viscosity, thus, the higher ML the easier the migration of carbon black. Meanwhile, DOP, CO, $\mathrm{DOP} / \mathrm{CO}$, and DOP/MACO (1:0) plasticizers give a similar tensile strength value. Raju et al. reported that $\mathrm{CO}$ is capable in increasing tensile strength of natural rubber compound when it is compared with naphthenic oil (Raju et al., 2007). However, in this study CO and DOP provide similar tensile strength.

The influence of the type of plasticizers on tear strength as shown in Fig. 5 is similar to the tensile strength. The addition of oil in combination with the cross-linked rubber phase of the NBR/PVC blends allows the production of soft compositions with good processability and elastic recovery (Wei et al., 2014). MACO also contains long chain unsaturated fatty acid ester which re- 
sults in two types of end chain reaction with the carbon black surface and nonpolar chain terminal interacted with the rubber molecule. According to Gujel et al. the interaction between the filler and elastomer is increased by the addition of vegetable oil (Gujel et al., 2014), or in this case, the addition of castor oil.

The influence of the type of plasticizers on tear strength as shown in Fig. 5 is similar to the tensile strength. The oil and the cross-linked rubber within NBR/PVC blend play an important role in providing a good process ability matrix as well as elastic recovery (Wei et al., 2014). MACO also contains long chain unsaturated fatty acid ester which results in two types of end chain reaction with the carbon black surface and nonpolar chain terminal interacted with the rubber molecule. According to Gujel et al., vegetable oil, or in this case is castor oil, will improve the interaction between filler and rubber matrix (Gujel et al., 2014).

A slight increase in tensile and tear strength was found in the NBR/PVC blended with MACO (1:1) sample upon thermal aging. Generally, rubber products are only cured to $90 \%$ and the remains portion are kept to facilitate addition crosslinking that formed during service. When they are subjected a thermal aging, the formation of additional crosslinking will be accelerated. However, excessive thermal aging will generate negative effect since it leads to degrade the crosslink itself, resulted in decreasing the mechanical properties (Elhamouly, 2010).

\section{CONCLUSIONS}

NBR/PVC blends are attractive because they have good mechanical performances. The use of MACO based plasticizer affects positively both cure characteristics and mechanical properties. These are shown by the higher CRI, similar viscosity, safe process level, and higher mechanical properties (hardness, elongation at break, tensile strength, and tear strength value) in compared to DOP. It is expected that MACO can become a potential candidate to substitute DOP plasticizer in NBR/PVC blends.

\section{ACKNOWLEDGEMENTS}

Authors would like to thank to the head of Center for Leather, Rubber, and Plastics, Ministry of Industry of the Republic of Indonesia for the financial support and to Prof. Evvy Kartini for the fruitful discussion.

\section{REFERENCES}

Al Minnath, M., Unnikrishnan, G., \& Purushothaman, E. (2011). Transport studies of thermoplastic polyurethane/natural rubber (TPU/NR) blends. Journal of Membrane Science, 379(1-2), 361-369, http://doi.org/10.1016/j.memsci.2011.06.006

Dasgupta, S., Agrawal, S. L., Bandyopadhyay, S., Chakraborty, S., Mukhopadhyay, R., Malkani, R. K., \& Ameta, S. C. (2007). Characterisation of eco-friendly processing aids for rubber compound: Part II. Polymer Testing, 27(3), 277-283, http:// doi.org/10.1016/j.polymertesting.2007.11.004

Dasgupta, S., Agrawal, S. L., Bandyopadhyay, S., Mukhopadhyay, R., Malkani, R. K., \& Ameta, S. C. (2009). Eco-friendly processing oils: A new tool to achieve the improved mileage in tyre tread. Polymer Testing, 28(3), 251-263, http:// doi.org/10.1016/j.polymertesting.2008.12.006

Elhamouly, S. H. (2010). Influences of accelerators on the structures \& properties on nitrile butadiene rubber. Modern Applied Science, 4(4), 47-61, http://dx.doi.org/10.5539/mas.v4n4p47

Erythropel, H. C., Brown, T., Maric, M., Nicell, J. A., Cooper, D. G., \& Leask, R. L. (2015). Designing greener plasticizers: Effects of alkyl chain length and branching on the biodegradation of maleate based plasticizers. Chemosphere, 134, 106-112, http://doi.org/10.1016/j. chemosphere.2015.04.014

Formela, K., \& Haponiuk, J. T. (2014). Curing characteristics, mechanical properties and morphology of butyl rubber filled with ground tire rubber (GTR). Iranian Polymer Journal (English Edition), 23(3), 185-194, http://doi.org/10.1007/s13726-013-0214-7

Ghorui, S., Bandyopadhyay, N. R., Ray, D., Sengupta, S., \& Kar, T. (2011). Use of maleated castor oil as biomodifier in unsaturated polyester resin/fly ash composites. Industrial Crops and Products, 34(1), 893-899, http://doi.org/10.1016/j.indcrop.2011.02.007

Gujel, A. A., Bandeira, M., Giovanela, M., Carli, L. N., Brandalise, R. N., \& Crespo, J. S. (2014). Development of bus body rubber profiles with additives from renewable sources: Part II - Chemical, physical-mechanical and aging characterization of elastomeric compositions. Materials and Design, 53, 1119-1123, http://doi.org/10.1016/j.matdes.2013.07.102

Ismail, H., Supri, S., \& Yusof, A. M. M. (2004). Blend of waste poly(vinylchloride) $(\mathrm{PVCw}) /$ acrylonitrile butadiene-rubber (NBR): The effect of maleic anhydride (MAH). Polymer Testing, 23(6), 675-683, http://doi.org/10.1016/j. polymertesting.2004.01.008

Jia, P. Y., Bo, C. Y., Zhang, L. Q., Hu, L. H., Zhang, M., \& Zhou, Y. H. (2015). Synthesis of castor oil 
based plasticizers containing flame retarded group and their application in poly (vinyl chloride) as secondary plasticizer. Journal of Industrial and Engineering Chemistry, 28, 217-224, http://doi.org/10.1016/j.jiec.2015.02.017

Jiang, D., Xin, C., Li, W., Chen, J., Li, F., Chu, Z., Shao, L. (2015). Quantitative analysis and health risk assessment of polycyclic aromatic hydrocarbons in edible vegetable oils marketed in Shandong of China. Food and Chemical Toxicology, 83, 61-7, http://doi.org/10.1016/j.fct.2015.06.001

Li, J. H., \& Ko, Y. C. (2012). Plasticizer incident and its health effects in Taiwan. Kaohsiung Journal of Medical Sciences, 28(7 SUPPL.), S17-S21. http://doi.org/10.1016/j.kjms.2012.05.005

Manoj, K. C., Kumari, P., \& Unnikrishnan, G. (2011). Cure characteristic, swelling behaviour, and mechanical properties of carbon black filler reinforced EPDM/NBR blend system. Journal of Applied Polymer Science, 120(5), 2654-2662.

Mazo, P., Rios, L., Estenoz, D., \& Sponton, M. (2012). Self-esterification of partially maleated castor oil using conventional and microwave heating. Chemical Engineering Journal, 185-186, 347351, http://doi.org/10.1016/j.cej.2012.01.099

Mistri, E., Routh, S., Ray, D., Sahoo, S., \& Misra, M. (2011). Green composites from maleated castor oil and jute fibres. Industrial Crops and Products, 34(1), 900-906, http://doi.org/10.1016/j.indcrop.2011.02.008

Nabil, H., Ismail, H., \& Azura, a. R. (2013). Compounding, mechanical and morphological properties of carbon-black-filled natural rubber/ recycled ethylene-propylene-diene-monomer (NR/R-EPDM) blends. Polymer Testing, 32(2), 385-393, $\quad$ http://doi.org/10.1016/j. polymertesting.2012.11.003

Raju, P., Nandanan, V., \& Kutty, K. N. (2007). A Study on the use of coconut oil as plasticiser in natural rubber compounds. Journal of Rubber Research, 10(1), 1-16.
Ray, D., Ghorui, S., Bandyopadhyay, N. R., Sengupta, S., \& Kar, T. (2012). New materials from maleated castor oil/epoxy resin blend reinforced with fly ash. Industrial and Engineering Chemistry Research, 51(6), 2603-2608, http://doi.org/10.1021/ie201472u

Sander, M. M., Nicolau, A., Guzatto, R., \& Samios, D. (2012). Plasticiser effect of oleic acid polyester on polyethylene and polypropylene. Polymer Testing, 31(8), 1077-1082, http://doi. org/10.1016/j.polymertesting.2012.08.006

Sankaran, K., Nando, G. B., Ramachandran, P., Nair, S., Govindan, U., Arayambath, S., \& Santanu, C. (2015). Influence of hybrid nanostructures and its tailoring mechanism on permeability, rheology, conductivity, and adhesion properties of a novel rubber blend nanocomposite. RSC Advances, (107), 87864-87875.

Shi, G., Cooper, D. G., \& Maric, M. (2011). Poly( $\varepsilon-$ caprolactone)-based "green" plasticizers for poly(vinyl choride). Polymer Degradation and Stability, 96(9), 1639-1647, http://doi. org/10.1016/j.polymdegradstab.2011.06.007

Singh, R., \& Bhattacharya, P. S. (2011). Cost-effective substitution of plasticizers in nitrile butadiene rubber vulcanizate with cashew nut shell oil. Rubber World, 243(6), 20-25.

Surya, I., Ismail,H., \&Azura,A. R. (2013).Alkanolamide as an accelerator, filler-dispersant and a plasticizer in silica-filled natural rubber compounds. Polymer Testing, 32(8), 1313-1321, http://doi. org/10.1016/j.polymertesting.2013.07.015

Wei, D., Zhao, J., Liu, T., \& Wang, Z. (2014). Mechanical and morphological properties of acrylonitrilebutadiene-styrene terpolymer/nitrile butadiene rubber thermoplastic vulcanizates plasticized by dioctyl phthalate. Journal of Thermoplastic Composite Materials, 29(3), 366-380, http://doi.org/10.1177/0892705713518796 
